\title{
DOCTORATES CONFERRED IN 1957
}

The following are among those who received doctorates in the mathematical sciences and related subjects from universities in the United States and Canada during 1957. In each case, the university, the month in which the degree was conferred, minor subjects (other than mathematics), and title of the dissertation are given.

Note that there is included at the end of these Notes a list of doctorates conferred in 1956 but not included last year.

A. H. Aaboe, Brown University, June, On Babylonian planetary theories.

W. R. Abel, University of Missouri, June, Metric properties of metric arcs.

I. J. Abrams, University of California, Berkeley, Contributions to the stochastic theory of inventory.

S. P. Agarwal, University of California, Berkeley, January, On the asymptotic equivalence of two classes of tests of a multiparameter hypothesis.

J. H. Alexander, The University of Tennessee, June, Approximately finite geometries and their coordinate rings.

R. L. Alonso, Harvard University, June, A special purpose digital calculator for the numerical solution of ordinary differential equations.

R. C. Alverson, Brown University, June, Elastic-plastic beam $d y$ namics by the method of characteristics.

J. J. Andrews, University of Georgia, June, Generalized winding numbers and light open maps.

P. M. Anselone, Oregon State College, June, minor in French; Convergency of the Wick-Chandrasekhar approximation technique in radiative transfer.

D. N. Arden, Purdue University, June, minor in physics, Curvatures of Riemannian manifolds.

W. O. Ash, Virginia Polytechnic Institute, Randomized estimates in power spectral analysis.

Silvio Aurora, Columbia University, May, Multiplicative norms of metric rings.

Joseph Auslander, University of Pennsylvania, June, Mean-Lstable systems.

G. E. Bartsch, Harvard, Confidence intervals for the means of nonnormal populations.

H. S. Bear, Jr., University of California, Berkeley, June, Complex function algebras. 
D. A. Beckwith, Brown University, June, An approximation method for plane gas flows.

W. C. Bennewitz, University of Illinois, June, minor in Philosophy, On Minkowski area.

W. S. Bicknell, University of Michigan, June, Premiums and reserves in multiple decrement theory.

C. M. Braden, University of Minnesota, December, minor in physics, Harmonic, biharmonic and related partial difference equations.

J. C. Bradford, The University of Oklahoma, August, Topological vector lattices.

Louis deBranges, III, Cornell University, June, Local operators on Fourier transforms.

D. W. Bressler, University of California, Berkeley, June, Absolutely measurable sets.

B. D. Bucher, Princeton University, April, The recovery of intervariety information in incomplete block designs.

R. C. Bzoch, Illinois Institute of Technology, June, On the existence and properties of the Lane integral.

Robert Canavan, New York University, June, Necessary conditions for continuation and reflection principles for solutions of homogeneous linear partial differential equations with constant coefficients.

R. L. Carter, The University of North Carolina, August, New designs for the exploration of response surfaces.

E. W. Cheney, Jr., The University of Kansas, June, On Gauge functions.

Y. T. Chou, Carnegie Institute of Technology, September, The effect of turbulence on slider-bearing lubrication.

D. L. Clark, Oregon State College, June, minor in physics, The distribution of linear functionals of stochastic processes.

Leonard Cohen, Columbia University, July, On mixed single sample experiments.

H. H. Corson, III, Duke University, June, minor in physics, Systems of equations in a finite field.

P. R. Culwell, The University of Texas, June, Iterated HolmgrenRiesz transforms in two dimensions.

R. T. Dames, University of Michigan, June, Stability and convergence for a numerical solution of the Goursat problem.

R. L. Davis, University of Michigan, June, Lie and Engle modules and their relation to Burnside's problem.

D. F. Dawson, The University of Texas, August, Continued fractions with absolutely convergent even or odd parts.

M. R. Demers, Brown University, June, On Lebesgue area. 
T. G. Donnelly, The University of North Carolina, June, $A$ family of sequential tests.

P. H. Doyle, III, The University of Tennessee, August, Tame, finite complexes in three-space.

C. E. Duncan, Stanford University, January, The asymptotic behavior of certain trigonometric sums.

J. D. Esary, University of California, Berkeley, A stochastic theory of accident survival and fatality.

R. E. Esch, Harvard University, June, The instablity of an unbounded parallel flow.

Solomon Feferman, University of California, Berkeley, June, Formal consistency proofs and interpretability of theories.

J. E. Forbes, Purdue University, January, minor in physics, Noncommutative finite groups with no irreducible representations of dimension higher than two.

W. R. Fuller, Purdue University, August, minor in physics, Existence theorems for periodic solutions of systems of differential and differential-difference equations.

A. E. Garrett, Virginia Polytechnic Institute, Estimation problems connected with stochastic processes.

A. M. Garsia, Stanford University, September, On surfaces with a rectilinear geodesic circle.

J. M. Gary, University of Michigan, February, Dualities in generalized manifolds and higher dimensional cyclic element theory.

Betty J. Gassner, New York University, February, On braid groups.

W. E. Gibson, Massachusetts Institute of Technology, September, minor in physics, Theory of unsteady laminar boundary layers.

Ramanathan Gnanadesikan, The University of North Carolina, June, Contributions to multivariate analysis including univariate and multivariate variance components analyis and factor analysis.

A. J. Goldman, Princeton University, January, A Cech theory of fundamental groups and covering spaces.

S. W. Golomb, Harvard University, June, Problems in the distribution of the prime numbers.

N. R. Goodman, Princeton University, June, The joint estimation of the spectra, cospectrum and quadrature spectrum of a two-dimensional stationary Gaussian process.

Roderick Gould, Harvard University, June, The application of graph theory to the synthesis of contact networks.

J. W. Gray, Stanford University, September, $A$ theory of pseudogroups with applications to contact structures. 
D. S. Greenstein, University of Pennsylvania, June, Derivative manifolds and Taylor series in the mean.

Geoffrey Gregory, Stanford University, An economic approach to the choice of continuous sampling plans.

R. R. Haering, McGill University, May, The electric and magnetic properties of graphite.

Susan Hahn, New York University, June, Stability criteria for difference schemes.

A. B. Hajian, Yale University, June, Measurable transformations and invariant measures.

D. W. Hall, Princeton University, January, Vacuum expectation values.

A. E. Hallerberg, University of Michigan, June, The development of the geometry of the fixed-compass with especial attention to the contribution of Georg Mohr.

Oma Hamara, Massachusetts Institute of Technology, June, minor in physics, Quadratic forms on infinite dimensional vector spaces.

Mary I. Hanania, University of California, Berkeley, June, Some statistical tests of hypotheses in learning theory.

D. K. Harrison, Princeton University, January, On torsion free Abelian groups.

H. A. Heckart, Iowa State College, June, Bursting speed of rotating discs.

R. L. Helmbold, Carnegie Institute of Technology, June, Semidiscrete potential theory.

L. H. Herbach, Columbia University, June, Optimum properties of analysis of variance tests based on Model II and some generalizations of Model II.

N. J. Hicks, Massachusetts Institute of Technology, February, minor in humanities, On the curvature and torsion of affine connexions.

C. J. Himmelberg, III, University of Notre Dame, June, $A$ nerw approach to absolute retracts and absolute neighborhood retracts.

S. P. Hoffman, Jr., Yale University, June, Second-order linear differential operators defined by irregular boundary conditions.

A. L. Hopkins, Jr., Harvard University, June, An investigation of non-ohmic resistive switching networks.

W. B. Houston, Jr., Massachusetts Institute of Technology, September, minor in physics, Curvature and torsion of fiber bundles.

H. V. Huneke, The University of Oklahoma, June, minor in physics, Some properties of the Nörlund methods as an ordered set.

L. C. Hunter, University of Oregon, June, On induced topologies in quasi-reflexive Banach spaces. 
Mohammad Iqbal, The University of North Carolina, June, On the classification statistic of Wald.

R. B. Jackson, Jr., Duke University, June, minor in education, Dependent solutions.

W. D. James, University of Illinois, June, minor in physics, Some potential representations in the plane.

J. G. Jewell, University of Pittsburgh, February, Essentiallyconvergent sequences and series.

E. S. Johnson, The Catholic University of America, June, minors in physics and education, Properties of solutions of nonlinear differential equations.

J. R. Johnson, Jr., Duke University, June, Minor in economics, Congruence properties of certain difference equations.

M. W. Johnson, Massachusetts Institute of Technology, September, minor in mechanical engineering, On the theory of thin elastic shells.

P. G. Johnson, University of Minnesota, Shares of functions with values in a Banach algebra.

G. H. Josie, Johns Hopkins University, Sampling variations as a factor in morbidity survey design.

R. P. Kanwal, Indiana University, June, minor in physics, Shock and wave surfaces for three-dimensional rotational gas flows.

M. L. Keedy, University of Nebraska, June, minors in physics and philosophy, Some properties of basic order relations in arithmetic of relation algebras.

R. P. Kelisky, The University of Texas, Interrelations between the numbers of Bell, Bernoulli, Euler, Fibonacci and Lucas.

May E. R. Kinsolving, Syracuse University, June, On spaces suitable for Finsler geometries in the large.

T. C. Kipps, University of California, Berkeley, June, The parametric problems for double integrals in the calculus of variations.

J. E. Kist, Purdue University, June, Topological ordered linear spaces.

J. K. Knowles, Massachusetts Institute of Technology, June, minor in physics, Thin elastic helicoidal shells.

C. W. Kohls, Purdue University, June, Ideals in rings of continuous functions.

Walter Koppelman, New York University, June, The RiemannHilbert theorem for finite Riemann surfaces.

C. Y. Kramer, Virginia Polytechnic Institute, June, Factorial treatments in incomplete block designs. 
H. C. Kranzer, New York University, February, Water waves prow duced by surface disturbances.

A. W. Kratzke, Oregon State College, June, minor in physics, First passage time distributions in electronic receivers.

Herbert Kurss, New York University, February, The solution to some turning point problems.

A. E. Labarre, Jr., The University of Oklahoma, June, minor in physics, Differential calculus in Hilbert spaces.

W. M. Laird, University of Pittsburgh, June, An analysis of continuous beam-columns with uniformly distributed axial loading.

J. W. Lamperti, California Institute of Technology, June, minor in philosophy, On the asymptotic behavior of recurrent and "almost recurrent" events.

H. J. Landau, Harvard University, June, On canonical conformal maps of multiply connected regions.

W. E. Langlois, Brown University, June, Steady flow of slightly visco-elastic fluids.

H. C. Lefkovits, The Rice Institute, May, Some applications of adherent series.

C. E. Leith, Jr., University of California, Berkeley, June, Onedimensional perturbation of unbounded self-adjoint operators.

C. J. Lewis, Brown University, June, The problem of Milloux for functions analytic in an open annulus.

Eric Liban, New York University, June, On mixed boundary value problems for elliptic equations in the plane.

H. M. Lieberstein, University of Maryland, February, minor in aeronautical engineering, On the generalized radiation problem of $A$. Weinstein.

J. C. Lillo, Princeton University, June, Almost periodic solutions of ordinary differential equations.

H. G. Loomis, The Pennsylvania State University, June, On a method of solving some partial differential equations.

K. R. Lucas, The University of Kansas, June, Submanifolds of dimension $(n-1)$ in $E^{n}$ with normals satisfying a Lipschitz condition.

Edith H. Luchins, University of Oregon, June, On some properties of certain Banach algebras.

R. J. Lundegard, Purdue University, January, minor in psychology, Identification and estimation in two stochastic models.

I. S. Luthar, University of Illinois, June, Uniqueness of the invariant mean on an Abelian semigroup.

Leo Lynch, Virginia Polytechnic Institute, On the analysis of paired ranked observations. 
J. J. Macdonnell, The Catholic University of America, June, minors physics and philosophy, Some convergence theorems for $\mathrm{Di}$ richlet-type series whose coefficients are entire functions of bounded index.

W. S. Mahavier, The University of Texas, January, minor in physics, $A$ theorem on spirals in the plane.

J. C. McCully, University of Michigan, February, The operational calculus of the Laguerre transform.

R. D. McWilliams, The University of Tennessee, minor in chemistry, June, Extensions of linear transformations.

Samuel Melamed, McGill University, October, Differential equations near a singular point.

William Mendenhall, North Carolina State College, Estimation of parameters of mixed exponentially distributed failure time distributions from censored life test data.

N. G. Meyers, Indiana University, September, minor in physics, Asymptotic behavior of solutions of linear elliptic differential equations.

D. W. Miller, University of Wisconsin, June, The structure of uniform semigroups.

P. D. Minton, North Carolina State College, Some distributions related to column totals in sociometric matrices.

Willard Miranker, New York University, February, The asymptotic theory of solutions of $\Delta u+k^{2} u=0$.

G. W. Morris, University of California, Los Angeles, June, On the first and second boundary value problems of thermo-elasticity for an ellipsoid of revolution.

R. D. Morrison, North Carolina State College, Some studies on the estimates of the exponents in models containing one and two exponentials.

W. O. J. Moser, University of Toronto, May, Abstract groups and geometrical configurations.

V. L. Mote, North Carolina State College, An investigation of the effect of misclassification on the $\chi^{2}$ tests in the analysis of categorical data.

J. W. Neuberger, The University of Texas, June, minor in physics, Continuous products and nonlinear integral equations.

August Newlander, New York University, June, Complex analytic structure for almost complex manifolds satisfying the integrability condition.

J. A. Nickel, Oregon State College, June, minor in physics, Plane wedge flow of a homogeneous incompressible isotropic Reiner-Rivlin fluid.

A. E. Nussbaum, Columbia University, May, The HausdorffBernstein Widder theorem of semi-groups in locally compact Abelian groups. 
R. R. O'Brien, Massachusetts Institute of Technology, June, minor in physics, $A$ singular perturbation of a boundary value problem for a third order differential equation.

E. S. O'Keefe, University of California, Berkeley, June, On the independence of primal algebras.

Norman Oler, McGill University, May, An inequality in the geometry of numbers.

M. W. Oliphant, The Catholic University of America, June, minors in physics and philosophy, Singular sets and Hausdorff measures.

Komorath Padmavally, The University of North Carolina, June, $A$ nonlinear integral equation.

M. V. Pai, Purdue University, June, minor in general engineering, Comparisons of the methods of classification.

E. T. Parker, The Ohio State University, March, On quadruply transitive groups.

H. L. Pearson, Illinois Institute of Technology, June, minor in mechanics, An extension of the concept of derivative with application.

R. N. Pederson, University of Minnesota, June, minor in physics, On the unique continuation theorem for certain elliptic partial differential equations.

R. N. Pendergrass, Virginia Polytechnic Institute, The rank analysis of triple comparisons.

Alfredo Pinero-Perez, University of Michigan, February, Légendre integral transforms.

W. J. Perry, The Pennsylvania State University, August, Mean value theorems for solutions of certain partial differential equations.

W. J. Pervin, University of Pittsburgh, February, Connected mappings of Hausdorff spaces.

D. P. Peterson, University of Oregon, June, Abstract Riemann sums on a compact group.

Gideon Peyser, New York University, February, Mixed initial and boundary problem of linear hyperbolic partial differential equations of higher order in two dimensions.

D. L. Phillips, Purdue University, June, minor in physics, Multiparabolic systems of partial differential equations.

George Pimbley, New York University, June, Solution of the initial value problem for the linearized multi-velocity transport equations with a slab geometry.

Vera S. Pless, Northwestern University, June, Quotient rings of continuous transformation rings.

I. P. Polonsky, New York University, June, Pseudo-analytic function with characteristic coefficients in $L_{p}$. 
H. L. Pond, The George Washington University, June, Some relations between input and output power spectra in certain nonlinear systems.

W. O. Portmann, Case Institute of Technology, June, Hausdorffanalytic functions of matrices and linear transformations.

G. C. E. Prins, University of Michigan, June, On the automorphism group of a tree.

S. E. Puckette, Yale University, June, Semigroups and unbounded difference operators.

M. O. Rabin, Princeton University, January, Recursive unsolvability of group theoretic problems.

James Radlow, New York University, June, Diffraction of a dipole field by a unidirectionally conducting screen.

E. R. Rang, University of Minnesota, December, minor in mechanics, Periodic solutions of singular perturbation problems.

R. R. Read, University of California, Berkeley, Contributions to the statistical theory of cloud chamber data.

H. J. Rebassoo, University of Wisconsin, June, Constant breadth curves on the sphere.

Dirk van der Reyden, North Carolina State College, The use of orthogonal polynomial contrasts in the confounding of factorial experiments.

R. H. Riffenburgh, Virginia Polytechnic Institute, Linear discriminant analysis.

D. S. Rim, Indiana University, June, Axioms for the cohomology theory of finite groups and cup product.

E. R. Rodemich, Stanford University, September, Flows with free boundaries in a tube.

J. I. Rosenblatt, Columbia University, Goodness-of-fit tests for approximate hypotheses.

A. I. Rosenfeld, Columbia University, April, Specializations in differential algebra.

M. J. Sane, University of California, Berkeley, Locally unbiased tests of composite hypotheses with s contraints.

D. W. Sasser, Yale University, June, On Jordan matrix algebras.

Martin Schechter, New York University, June, On estimating partial differential operators in the $L_{2}$ norm.

J. F. Schell, Indiana University, September, minor in physics, Intrinsic deformation theory of a family of subspaces in a Riemann space.

J. E. Scroggs, The Rice Institute, May, On invariant subspaces of a normal operator. 
J. F. Seewerker, University of California, Los Angeles, June, The extendability of Riemann surface.

R. J. Semple, Princeton University, April, Cohomology with unit coefficients in local fields.

N. E. Sexauer, University of Illinois, October, Some results concerning transformation rings which satisfy various density conditions.

Patrick Shanahan, Indiana University, September, $A n$ axiomatic characterization of the reduced homology theory.

Lena Sharney, New York University, June, Some results in combinatorial set theory.

P. W. Shaw, Stanford University, September, Variational methods in conformal mappings with applications to hydrodynamics.

E. P. Shelly, Carnegie Institute of Technology, June, Difference equations of polyharmonic type.

F. A. Sherk, University of Toronto, November, The theory of regular maps.

M. M. Siddiqui, The University of North Carolina, June, Distributions of some serial correlation coefficients.

F. B. Sleator, New York University, February, $A$ variational solution to the problem of scalar scattering by a prolate spheroid.

Daniel Slotnick, New York University, June, Asymptotic behavior of solutions of canonical systems near a closed unstable orbit.

Stephen Smale, University of Michigan, February, Regular curves on Riemannian manifolds.

D. L. Smith, The University of Rochester, June, Uniqueness theory for Laguerre series.

J. W. Smith, Columbia University, November, Stability of quasilinear differential equations.

M. B. Smith, Jr., The University of North Carolina, June, $A n$ investigation of normal spaces.

R. B. Smith, Yale University, June, Representation of certain algebras on Hilbert space.

J. H. Stapleton, Purdue University, June, minor in psychology, On the theory of asymptotic distributions (mod.) and its extension to abstract spaces.

N. B. Stein, Cornell University, June, The third obstruction in complex projective spaces.

G. R. Strohl, Jr., University of Maryland, August, Peano spaces which are either strongly cyclic or two-cyclic.

R. G. Swan, Princeton University, June, Spaces with finite groups of transformations. 
E. W. Swokowski, University of Wisconsin, June, On the theory of certain Lie rings of skew elements.

M. F. Tinsley, The Ohio State University, December, Permanents of cyclic matrices.

Anthony Trampus, Case Institute of Technology, June, Differentiability and analyticity of functions in linear algebras.

Peter Treuenfels, New York University, June, Exponential decay of solutions of certain linear partial differential equations.

E. F. Trombley, University of Cincinnati, June, Maximum theorems for Hilbert transforms in one and two variables.

J. P. Tull, University of Illinois, June, minor in physics, Dirichlet multiplication in lattice point problems.

L. H. Turner, Purdue University, August, The direct method in the calculus of variations.

J. B. Tysver, University of Michigan, June, Inherent errors in matrices with statistical applications.

S. I. Vrooman, University of Pittsburgh, February, Involutions in the plane of two complex variables.

J. W. Walker, The University of North Carolina, June, Optimal decomposition of a sample space for estimations based on grouped data.

A. I. Weinzweig, Harvard University, June, On fibre spaces and fibre bundles.

E. F. Whittlesey, Princeton University, January, Classification of finite 2-complexes.

J. B. Wilson, University of Florida, June, minor in engineering mechanics, $A n$ orthotropic circular disk subjected to its own weight when supported at a point.

Eric Wolman, Harvard University, June, Optimum difference operators for digital control systems.

Maria J. Wonenburger, Yale University, June, On the group of similitudes and its projective group.

L. T. Wos, University of Illinois, June, minor in philosophy, On commutative prime power subgroups of the norm.

R. L. Yates, University of Florida, June, minor in philosophy, On Waring's problem with cubic functions.

J. J. Yeh, University of Minnesota, December, Nonlinear Volterra functional equations and linear parabolic differential systems.

Peter Yff, University of Illinois, October, minor in geology, On line complexes in a projective four-space.

L. N. Zaccaro, Syracuse University, June, $A$ problem-sequence development of introductory topology. 
P. A. Zaphr, University of Pittsburgh, June, An examination of Euler methods of summability for double series.

E. M. Zaustinsky, University of Southern California, June, Spaces with nonsymmetric distance.

David Zeitlin, University of Minnesota, August, Behavior of conformal maps under analytic deformation of the domain.

Alexis Zinger, University of Montreal, On the choice of the best amongst three normal populations with known variances.

The following doctorates were conferred in 1956, but were not included in the list in the preceding volume of this Bulletin (vol. 63, pp. 210-221):

A. W. Adler, University of California, Los Angeles, August, Characteristic classes of homogeneous spaces.

Olive J. Dunn, University of California, Los Angeles, August, Estimation problems for dependent regression.

R. L. Dunn, University of California, Los Angeles, August, Setvalued functions without fixed points.

D. A. Pope, University of California, Los Angeles, August, The approximation of function spaces and some applications to the numerical analysis of problems in the calculus of variations.

D. W. Robinson, Case Institute of Technology, June, Functions of commutable linear transformations. 